\title{
ГЕОЭКОЛОГИЧЕСКИЙ ПОДХОД К ОБОСНОВАНИЮ ВЫБОРА ПЛОЩАДОК ТЕПЛОЭЛЕКТРОСТАНЦИЙ (НА ПРИМЕРЕ СТРОИТЕЛЬСТВА САХАЛИИНСКОЙ ГРЭС-2)
}

\author{
М. И. Саввин \\ Институт АО «Теплоэлектропроект», г. Москва \\ Поступила в редакцию 18 июля 2019 г.
}

\begin{abstract}
Аннотация: в статье рассматривается геоэкологический подход к обоснованию выбора площадок теплоэлектростанций. Этот подход отличается от других тем, что учитывает неблагоприятные изменения природной среды, которые могут повлечь за собой строительство и функиионирование объектов теплоэнергетики. В основе подхода выделены четыре группы критериев обоснования выбора площадки строительства: эколого-географические критерии, инженерногеологические условия, общие принципы размещения, технологические особенности с учетом экологических требований. Этот подход был применен для геоэкологического обоснования выбора оптимальной площадки на примере размещения Сахалинской ГРЭС-2.
\end{abstract}

Ключевые слова: объекты теплоэнергетики, неблагоприятные изменения природной среды, выбор площадок для строительства, критерии оптимальной площадки для строительства.

\section{GEOECOLOGICAL APPROACH TO JUSTIFICATION OF THE CHOICE OF THERMOELECTRIC POWER STATIONS SITE AREAS (ON THE EXAMPLE OF THE CONSTRUCTION OF SAKHALIN GRES-2)}

\begin{abstract}
: the article deals with geoecological approach to justification of the choice of thermoelectric power stations site areas. This approach differs from the other ones in the point that it takes into account unfavorable changes of natural environment, that can be caused by the construction and functioning of heat power facilities. Four groups of criteria for justification of the choice of the construction site area were singled out: the ecological-geographic criteria, engineering-geological conditions, general principles of location, technological peculiarities regarding ecological requirements. This approach was used in geoecological justification of the choice of optimal site area on the example of placing Sakhalin GRES-2.

Key words: heat power facilities, unfavorable changes of natural environment, choice of the construction site areas, criteria for the choice of optimal construction site area.
\end{abstract}

\section{Введение}

В связи со строительством энергетических объектов, чаще всего, теплоэлектростанций, возникает вопрос выбора при размещении оптимальной, с точки зрения снижения экологических рисков, площадки.

Для выявления неблагоприятных изменений природной среды, которые может повлечь строительство и функционирование объектов теплоэнергетики, используются различные теоретические подходы.

Эколого-географический подход (применительно к конкретной территории с учетом ее природных и техногенных особенностей) разработан в трудах В. Н. Башкина, Г. Л. Кофф, В. И. Кружалина, С. М. Мягкова и др. [1-4].

Экологические и социокультурные риски строительства и эксплуатации объектов теплоэнергетики рассмотрены в работах С. М. Мягкова, В. Н. Башкина и др. $[1,2,5]$. Они затрагивают следующие аспекты: выбор основного вида топлива как фактор загрязнения окружающей среды, изменение в структуре землепользования, нарушение растительного и животного мира, физическое и химическое загрязнение атмосферы, изменения в традиционном природопользовании коренных малочисленных народов и утрата культурного наследия.

Методика, предложенная Н. Н. Клюевым в 1996 г. [6], позволяет провести геоэкологический анализ размещения экологически опасных отраслей промышленности. Исходными данными для анализа возможных вариантов размещения, согласно методике Н. Н. Клюева, являются технологические особенности, информация об эколого-географическом положении объекта и характеристика экологической ситуации в регионе, где выделяются следующие социальные по- 
казатели: рассредоточение населения в ареале экологической активности объекта; размещение культурных ценностей; экономические показатели: величина, структура и размещение хозяйственного потенциала.

Следует заметить, что методики Н. Н. Клюева и С. М. Мягкова во многом сходны, хотя имеют некоторые незначительные различия. Так, методика С. М. Мягкова в отличие от других, в первую очередь, отражает степень опасности для социума, и лишь опосредованно для растительности и животного мира.

За рубежом проблема размещения объектов энергетики (и анализ связанных с ними изменений) получила развитие в работах Р. Кини [7]. Р. Кини акцентирует внимание на следующих вопросах: природные и климатические условия, масштабы расстояний и территорий, охваченных энергетическим строительством, существование альтернатив для выбора типов энергетических объектов и площадок под них, техногенные нагрузки на окружающую среду, сохранение природных и ландшафтных ценностей при энергетическом строительстве и т.д.

При этом проблема размещения объектов энергетики, на наш взгляд, охвачена недостаточно.

\section{Результаты исследования}

На основе систематизации изученных материалов, нормативной документации и анализа базы данных AO «Институт Теплоэлектропроект» по выбору площадок объектов теплоэлектроэнергетики, нами разработан подход к обоснованию выбора площадок для строительства предприятий теплоэлектроэнергетики, включающий авторские дополнения и уточнения к существующим методикам (Н. Н. Клюева и С. М. Мягкова [6, 7]).

В стратегических ориентирах, определяющих размещение станции, помимо предложенных $\mathrm{H}$. Н. Клюевым показателей, дополнительно учитываются: преобладающее направление ветра, категория земель, отводимых под строительство, доступ к инженерным коммуникациям, наличие охраняемых природных территорий и видов животного и растительного мира, требования существующего природоохранного законодательства и нормативной документации.

В нормативной документации на проведение инженерных изысканий [8] и в работах В. Т Трофимова [9], А. Ф. Брюхань, Ф. Ф. Брюхань, А. Д. Потапова [10] выявлены критерии исходных данных для исследования природной среды, по которым следует проводить инженерные изыскания для всех объектов капитального строительства. Однако в этих работах отсутствуют система балльной оценки и ранжирование критериев по значимости при размещении объектов теплоэлектроэнергетики.

Представляется целесообразным выделить четыре группы критериев обоснования выбора площадки строительства: эколого-географические критерии, инженерно-геологические условия, общие принципы размещения, технологические особенности с учетом экологических требований. Всего в указанные блоки входит 33 критерия значимости. Они условно оценены нами (в сумме $100 \%=1$ ).

Методика определения весовых критериев заключалась в закономерности, чем сильнее влияние того или иного фактора на групповой элемент системы оценки, тем больше «вес» этого фактора.

В ходе обобщения опытных материалов и статистических данных АО «Институт Теплоэлектропроект» по выбору площадок объектов теплоэлектроэнергетики методом экспертной оценки нами установлена самая большая значимость («вес») критериев у инженерно-геологической группы $(0,35)$. В инженерно-геологической группе определяющее значение имеет сейсмичность $(0,07)$, так как она может повлиять на развитие оползневых процессов и изменение режима поверхностных вод (смещение пластов или преграда в случае обвала рек/ручьев, используемых технического водоснабжения). Не менее важным критерием, усложняющим строительство, является наличие многолетнемерзлых грунтов (вечной мерзлоты $-0,05)$. Далее по вкладу в результат следуют: затопляемость $(0,032)$, наличие специфических грунтов $(0,032)$ и характер грунтовых вод $(0,031)$.

Инженерно-геологическая группа критериев очень близко коррелирует с эколого-географической $(0,34)$, включая эколого-геологические подходы, где самый большой вес имеют: наличие краснокнижных видов животных $(0,045)$, затем потеря земельных ресурсов, (выбор места размещения площадки строительства на менее плодородных почвах с максимальным сохранением лесного фонда), нарушения растительного и животного мира $(0,043)$, затем соблюдение гигиенических нормативов $(0,039)$, санитарно-защитной зоны $(0,036)$ и экологическая ситуация: потенциал загрязнения атмосферы и коэффициент рельефа местности $(0,035)$, фоновых концентраций загрязняющих веществ в атмосферном воздухе и оценке современного экологического состояния почв (грунтов), в том числе уровня их загрязнения для соответствующих видов функционального использования в зависимости от загрязнения $(0,034)$.

Среди технологической группы критериев с учетом экологических требований $(0,197)$ определяющим является вид топлива $(0,07)$, и в связи с этим наличие/отсутствие золошлакоотвалов $(0,03)$ и выбор систем водоснабжения $(0,021)$.

Критерии общих принципов размещения $(0,113)$ базируются на транспортной доступности $(0,023)$, возможности использования уже нарушенных (освоенных) территорий $(0,031)$ и использованием социальной среды $(0,025)$.

На основании значений критериев обоснования выбора (всего 33 критерия) была введена система баллов $(1,2,3)$. Для выбора приоритетного варианта строительства по различным весовым критериям использована упрощенная трехбалльная система оценки вариантов: 
3 балла - расположение площадки наиболее благоприятно по данному критерию или является определяющим для данной площадки;

2 балла - рассматриваемый критерий условноблагоприятный или не является определяющим для данной площадки;

1 балл - расположение площадки неблагоприятно по данному критерию.

В методике рассчитывается оптимальный балл (Об) с учетом значимости критерия (100\% или 1) и рассчитывается по формуле:

$$
\text { Об }=\alpha_{1} \cdot \chi_{1}+\alpha_{2} \cdot \chi_{2}+\alpha_{3} \cdot \chi_{3}+\alpha_{n} \cdot \chi_{n} \text {, где }
$$

Об - оптимальный балл,

$\alpha_{n}$ - выбранный балл по критериям оценки,

$\chi_{n}$ - значимость критерия оценки.

Величина оптимального бала получена по результатам проектирования объектов ТЭС в различных регионах страны с неоднородными природно-климатическими условиями:

- Джубгинской ТЭС, Якутской ГРЭС-2, Южноуральской ГРЭС-2, функционирующих на природном газе, расположенных на неосвоенной территории (новое строительство).

- Создание двух новых энергоблоков Троицкой ГРЭС, функционирующей на каменном угле, расположенных на существующей площадке Троицкой
ГРЭС с действующим золоотвалом.

В соответствии с предложенной методикой, для условий размещения объектов теплоэлектроэнергетики по геоэкологическому анализу и статистическим данным АО «Институт Теплоэлектропроект», предлагается ввести следующую градацию по величине оптимального балла для размещения: благоприятные (Об > 2,3), условно-благоприятные $(2 \leq$ Об $<2,3)$ и неблагоприятные $(О б<2)$.

В качестве примера предлагается рассмотреть строящуюся Сахалинскую ГРЭС-2 (СГРЭС-2) в Сахалинской области.

Итак, рассмотрим три варианта размещения: 1) в районе пос. Ильинский Томаринского района на западном побережье Сахалина; 2) рядом с угольным месторождением в Углегорском муниципальном районе; 3) на берегу залива Терпения в Поронайском районе, в рамках расширения существующей Сахалинской ГРЭС-1.

Риски строительства и анализ сравнительных физико-географических условий размещения СГРЭС-2 исследованы ранее [11].

Оценка выбора приоритетного варианта строительства в соответствии с авторской методикой обоснования выбора с учетом сравнительного анализа для трех площадок размещения по эколого-географическим, геологическим и технологическим критериям приведена в табл. 1

Таблица 1

Обоснование оптимального размещения Сахалинской ГРЭС-2

\begin{tabular}{|c|c|c|c|c|c|}
\hline \multirow{2}{*}{$\begin{array}{c}\text { № } \\
\text { кри- } \\
\text { те- } \\
\text { рия } \\
\text { п/п }\end{array}$} & \multirow[b]{2}{*}{ Критерий оценки } & \multirow{2}{*}{$\begin{array}{l}\text { Значи- } \\
\text { мость } \\
\text { крите- } \\
\text { рия }\end{array}$} & \multicolumn{3}{|c|}{$\begin{array}{c}\text { Оценочные баллы по вариантам размещения } \\
\text { Сахалинской ГРЭС-2 }\end{array}$} \\
\hline & & & $\begin{array}{c}\text { Площадка в } \\
\text { Углегорском } \\
\text { районе } \\
\end{array}$ & $\begin{array}{c}\text { Площадка в } \\
\text { Томарин- } \\
\text { ском районе }\end{array}$ & $\begin{array}{c}\text { Площадка в Поро- } \\
\text { найском районе } \\
\text { (вблизи СГРЭС-1) }\end{array}$ \\
\hline 1 & 2 & 3 & 4 & 5 & 6 \\
\hline 1 & Потенциал загрязнения атмосферы & 0,035 & 3 & 3 & 3 \\
\hline 2 & $\begin{array}{l}\text { Наличие объектов с нормируемыми показателями } \\
\text { атмосферного воздуха (дет. сады, садовые и ого- } \\
\text { родные участки) }\end{array}$ & 0,039 & 3 & 3 & 3 \\
\hline 3 & $\begin{array}{l}\text { Характеристика рельефа предполагаемой промыш- } \\
\text { ленной площадки }\end{array}$ & 0,03 & 1 & 2 & 3 \\
\hline 4 & $\begin{array}{l}\text { Экологическая ситуация, «фоновые концентрации } \\
\text { загрязняющих веществ» }\end{array}$ & 0,034 & 3 & 3 & 2 \\
\hline 5 & $\begin{array}{l}\text { Соблюдение Санитарной зоны (С33) между про- } \\
\text { мышленной площадкой ТЭС и жилой зоной (по } \\
\text { фактору химического и физического воздействия) }\end{array}$ & 0,036 & 3 & 3 & 2 \\
\hline 6 & $\begin{array}{l}\text { Наличие зон с особым режимом использования } \\
\text { территории }\end{array}$ & 0,038 & 3 & 2 & 3 \\
\hline 7 & $\begin{array}{l}\text { Наличие на площадке водных объектов: рек, ручь- } \\
\text { ев, временных водотоков }\end{array}$ & 0,04 & 1 & 2 & 1 \\
\hline 8 & $\begin{array}{l}\text { Наличие в районе площадок миграционных путей } \\
\text { объектов животного мира (в том числе внесенных в } \\
\text { Красные книги) }\end{array}$ & 0,045 & 1 & 2 & 3 \\
\hline 9 & $\begin{array}{l}\text { Потеря земельных ресурсов. Прогнозируемые } \\
\text { нарушения растительного и животного мира }\end{array}$ & 0,043 & 2 & 2 & 3 \\
\hline 10 & Тип грунтов и допускаемое давление на грунт & 0,012 & 2 & 2 & 2 \\
\hline
\end{tabular}


Продолжение табл. 1

\begin{tabular}{|c|c|c|c|c|c|}
\hline 1 & 2 & 3 & 4 & 5 & 6 \\
\hline 11 & Фильтрационные свойства верхней толщи грунтов & 0,025 & 2 & 3 & 1 \\
\hline 12 & Характер грунтовых вод & 0,031 & 2 & 2 & 1 \\
\hline 13 & Затопляемость & 0,032 & 2 & 2 & 2 \\
\hline 14 & Сейсмичность & 0,07 & 1 & 1 & 2 \\
\hline 15 & Оползневая устойчивость & 0,038 & 1 & 2 & 3 \\
\hline 16 & $\begin{array}{l}\text { Многолетнемерзлые грунты } \\
\text { (вечная мерзлота) }\end{array}$ & 0,05 & 3 & 3 & 3 \\
\hline 17 & $\begin{array}{l}\text { Наличие специфических грунтов (просадочных, } \\
\text { набухающих, органо-минеральных, засоленных, } \\
\text { элювиальных, техногенных) }\end{array}$ & 0,032 & 2 & 2 & 1 \\
\hline 18 & Карст & 0,025 & 3 & 3 & 3 \\
\hline 19 & Просадочность (для глинистых грунтов) & 0,022 & 3 & 3 & 3 \\
\hline 20 & Снежные и каменные обвалы & 0,013 & 3 & 3 & 3 \\
\hline 21 & $\begin{array}{l}\text { Социальная среда, наличие квалифицированного } \\
\text { персонала }\end{array}$ & 0,025 & 1 & 1 & 3 \\
\hline 22 & $\begin{array}{l}\text { Обращение с отходами (обезвреживание, обработ- } \\
\text { ка, размещение, захоронение) }\end{array}$ & 0,018 & 2 & 2 & 2 \\
\hline 23 & $\begin{array}{l}\text { Освоение территории. } \\
\text { Возможность использования нарушенных террито- } \\
\text { рий для нового строительства }\end{array}$ & 0,031 & 1 & 1 & 3 \\
\hline 24 & Транспортная доступность & 0,023 & 2 & 1 & 3 \\
\hline 25 & Наличие месторождений строительных материалов & 0,016 & 2 & 2 & 2 \\
\hline 26 & $\begin{array}{l}\text { Тип местности (по фактору ветрового воздействия } \\
\text { на сооружения) }\end{array}$ & 0,012 & 1 & 2 & 2 \\
\hline 27 & $\begin{array}{l}\text { Абсолютная минимальная температура атмосферно- } \\
\text { го воздуха (для размещения технологического обо- } \\
\text { рудования) }\end{array}$ & 0,011 & 3 & 3 & 3 \\
\hline 28 & $\begin{array}{l}\text { Размеры площадки и конфигурация (оптимальность } \\
\text { компоновки) }\end{array}$ & 0,018 & 1 & 1 & 2 \\
\hline 29 & Система охлаждения (техническое водоснабжение) & 0,021 & 3 & 3 & 1 \\
\hline 30 & $\begin{array}{l}\text { Характеристика водных источников района для } \\
\text { питьевого водоснабжения электростанции }\end{array}$ & 0,02 & 2 & 2 & 3 \\
\hline 31 & Организация охраны водного бассейна & 0,015 & 1 & 1 & 3 \\
\hline 32 & Вид топлива & 0,07 & 2 & 2 & 2 \\
\hline 33 & $\begin{array}{l}\text { * Загрязнение отходами, золошлакоудаление (при } \\
\text { использовании в качестве основного вида топлива: } \\
\text { уголь, нефтяной кокс) }\end{array}$ & 0,03 & 2 & 2 & 1 \\
\hline & Итого & 1 & 67 & 71 & 77 \\
\hline & Итого по величине Об & & 2 & 2,129 & 2,324 \\
\hline
\end{tabular}

\section{Заключение}

Предложенный геоэкологический подход для обоснования выбора оптимальной площадки для теплоэлектростанций, применительно к размещению СГРЭС-2, показал, что по совокупности имеющихся материалов (сейсмичность, грунтовые условия, наличие источника технического водоснабжения, наличие подъездных дорог и др.) исследуемая площадка в Томаринском районе вблизи пос. Ильинский является условно-благоприятной (по суммарному количеству баллов - 71 и Об - 2,129).

Преимущества площадки вблизи г. Углегорска не выглядят резонными из-за высокой сейсмической активности и очагов землетрясения этого района (суммарный бал 67 и Об равным 2), хотя с точки зрения способа доставки угля и расстояния транспортирования приоритетной следует считать именно ее. Наиболее благоприятной площадкой для строительства (по суммарному количеству баллов - 77 и Об - 2,324) является площадка Сахалинской ГРЭС.

Несомненно, данный геэкологический подход может применяться для анализа выбора площадки строительства объектов теплоэлектроэнергетики и на любой другой географической территории. 


\section{ЛИТЕРАТУРА}

1. Башкин, В. Н. Управление экологическим риском / В.

Н. Башкин. - М.: Научный мир, 2005. - 368 с.

2. Башкин, В. Н. Методологические основы оценки критических нагрузок поллютантов на городские экосистемы / В.

Н. Башкин, А. С. Курбатова, Д. С. Савин - М.: Науч.-исслед. и проект.-изыскат. ин-т экологии, $2004-64$ с.

3. Инженерно-геоморфологические аспекты составления карты социально-геологического риска / Г. Л. Кофф [и др.]

// Инженерная география. Инженерно-геоморфологические аспекты. - СПб: Изд-во РГО, 1992. - С. 52-53.

4. Кружалин, В. И. Инженерная геоморфология / В.

И. Кружалин, Ю. Г. Симонов. - М.: Изд-во МГУ, 1993. $208 \mathrm{c}$.

5. Мягков, C. M. География природного риска / С. М. Мягков. - М.: Изд-во МГУ, 1995.- 258 с.

6. Клюев, Н. Н. Эколого-географическое положение России и ее регионов : автореф. дис. докт. геогр. наук : 11.00.02. / Клюев Николай Николаевич. - М., 1996. - 46 с.

7. Кини, Р. Размещение энергетических объектов: выбор решений / Р. Кини / Пер. с англ. - М.: Энергоатомиздат,

$A O$ «Институт Теплоэлектропроект», г. Москва

Саввин Максим Игоревич, начальник группь

E-mail: geomax02@mail.ru

Тел: +7 (495) 9846200 (доб. 4780)
1983. $-320 \mathrm{c}$.

11. Свод правил «Инженерные изыскания для строительства. Основные положения» 47.13330.2012. Актуализированная редакция СНиП 11-02-96. Утвержден приказом Федерального агентства по строительству и жилищнокоммунальному хозяйству (Госстрой России) от 10 декабря 2012 г. N 83/ГС и введен в действие с 1 июля 2013 г. [Электронный ресурс]. - Режим доступа: http://docs.cntd.ru/ document/1200096789 (дата обращения 23.08.2019).

9. Трофимов, В. Т. Содержание, объект и предмет экологической геологии / В. Т. Трофимов, Д. Г. Зилинг // Программа «Университеты России». Геология. - Книга 2. - М.: Издво МГУ, 1995. - С. 89-96.

10. Брюхань, А. Ф. Инженерно-экологические изыскания для строительства теплових электростанций / А. Ф. Брюхань, Ф. Ф. Брюхань, А. Д. Потапов. - М.: АСВ, 2010. - 192 с. 11. Саввин, М. И. Риски строительства и эксплуатации объектов теплоэнергетики (на примере Сахалинской области) / М. И. Саввин // География и природные ресурсы. - 2016. № 1. - С. 46-54.

Teploelektroproekt institute, Moscow

Savvin M. I., head of the group

E-mail: geomax02@mail.ru

Tel.: +7 (495) 984-62-00 (ext. 4780 